\title{
RANTES Secretion by Gene-Modified Tumor Cells Results in Loss of Tumorigenicity In Vivo: Role of Immune Cell Subpopulations
}

\author{
JAMES J. MULÉ,,$^{1,3}$ MARY CUSTER, ${ }^{1}$ BRUCE AVERBOOK, ${ }^{1}$ JAMES C. YANG, ${ }^{1}$ JEFFREY S. WEBER, ${ }^{1}$ \\ DAVID V. GOEDDEL, ${ }^{2,4}$ STEVEN A. ROSENBERG, ${ }^{1}$ and THOMAS J. SCHALL ${ }^{2,5}$
}

\begin{abstract}
An immunogenic murine fibrosarcoma cell line was genetically modified to express and produce the human RANTES chemokine stably. In in vitro chemotaxis assays purified recombinant human RANTES as well as human RANTES secreted by the modified murine tumor cells were strongly chemoattractant for mouse $\mathrm{CD8}^{+}$ /Thy-1 ${ }^{+}$tumor-infiltrating lymphocytes (TIL). RANTES production did not alter the growth of these cytokine gene-modified tumor cells in vitro, but injection of RANTES-secreting cells resulted in the abolition of the ability of those cells to form solid tumors in vivo. The growth of tumors could be restored by co-administration of monoclonal antibodies that inhibit the function of various subsets of immune cells. For example, depletion of $\mathrm{CD8}^{+} \mathrm{T}$ cells by antibody administration resulted in complete restoration of solid tumor formation by RANTES-secreting cells, whereas depletion of the $\mathrm{CD4}^{+} \mathrm{T}$ cell population resulted in a partial restoration of tumor formation. Additionally, administration of an anti-CR3 monoclonal antibody known to inhibit the in vivo migration of macrophages also completely restored the tumorigenicity of RANTES-secreting fibrosarcoma cells. Thus, the human RANTES chemokine can abolish tumorigenicity of an immunogenic fibrosarcoma in an in vivo murine model, and this process is mediated by various subpopulations of immune effector cells.
\end{abstract}

\section{OVERVIEW SUMMARY}

Members of the chemokine superfamily mediate potent and selective chemoattraction of a variety of immune cell subsets, which is concentration dependent. This important and novel biologic activity raises the possibility of using chemokines as adjuvants in cancer vaccine strategies. We describe here the in vitro chemotactic capacity of RANTES for murine $\mathrm{CDB}^{+}$tumor-infiltrating lymphocytes (TIL). Moreover, murine fibrosarcoma cells transfected with the cDNA encoding RANTES and secreting high levels of this chemokine become nontumorigenic in immunocompetent mice. The antitumor effect of RANTES is dependent on inherent tumor inmunogenicity and is mediated through the participation of host-derived $T$ cells and macrophages. Thus, the general chemoattractant properties exhibited by RANTES in vitro appear to be relevant in an in vivo model. These data warrant further investigation of other distinct members of the chemokine superfamily for their potential use, either alone or in combination, in gene therapy approaches that employ tumor cells as immunogens.

\section{INTRODUCTION}

$\mathbf{T}$ HE CHEMOKINES ARE A TRIPARTITE SUPERFAMILY of immune proteins with proinflammatory properties (Oppenheim et al., 1991; Schall, 1991; Kelner et al., 1994). The structural distinction that divides the superfamily into its three subgroups, $\mathrm{C}-\mathrm{X}$ $\mathrm{C}, \mathrm{C}-\mathrm{C}$, and, most recently, $\mathrm{C}$, has also been shown to delineate a general, although not absolute, distinction in the biological properties of these molecules that is dose dependent (Schall, 1991; Kelner et al., 1994). Whereas most C-X-C chemokines tend to attract and activate neutrophils but not monocytes, the $\mathrm{C}$ $\mathrm{C}$ chemokines appear to attract monocytes but not neutrophils (Schall, 1994). This distinction appears to be reflected by a speci-

\footnotetext{
${ }^{1}$ Surgery Branch, National Cancer Institute, National Institutes of Health, Bethesda, MD 20892.

${ }^{2}$ Genentech, Inc., South San Francisco, CA.

New addresses: ${ }^{3}$ University of Michigan Medical Center, Ann Arbor, MI 48109-0666; ${ }^{4}$ Tularik Pharmaceuticals, South San Francisco, CA 94080; 5 DNAX Research Institute, 901 California Ave., Palo Alto, CA 94304.
} 
ficity at the level of the cloned receptors for these two classes of molecules, where $\mathrm{C}-\mathrm{C}$ chemokine receptors have been shown not to bind C-X-C molecules and vice versa (Holmes et al., 1991; Murphy and Tiffany, 1991; Gao et al., 1993; Neote et al., 1993; Schall, 1994 and unpublished observation).

The actions of the $\mathrm{C}-\mathrm{C}$ chemokines are not limited to monocytes, however. Various members of the $\mathrm{C}-\mathrm{C}$ chemokine family have been shown to act differentially on basophils [monocyte chemotactic protein-1 (MCP-1) and RANTES; Bischoff et al., 1992; Kuna et al., 1992a,b] and eosinophils (RANTES and MIP$1 \alpha$; Kameyoshi et al., 1992; Rot et al., 1992). Of particular interest is the effect of the C-C chemokines on lymphocytes. RANTES was first shown to be a chemoattractant for memory T cells in vitro (Schall et al., 1990), and these findings have been extended to show that other $\mathrm{C}-\mathrm{C}$ chemokines preferentially attract different lymphocyte subpopulations (Schall et al., 1993; Taub et al., 1993). The proadhesive properties for some of the C-C chemokines on lymphocytes have also been documented (Tanaka et al., 1993; Taub et al., 1993). Recently, the C chemokine member, lymphotactin, has been cloned molecularly (Kelner et al., 1994; Kennedy et al., 1995). Lymphotactin clearly lacks the first and third cysteines in the four-cysteine motif, but shares a great deal of amino acid similarity at its carboxyl terminus with C-C chemokines. Lymphotactin is the only superfamily member to date to be selectively chemotactic to lymphocytes, as it does not attract either monocytes or neutrophils (Kelner et al., 1994; Kennedy et al., 1995). Thus, the chemokines could be involved in imparting leukkocyte subset specificity in immune cell trafficking processes, and chemokines may be key links between lymphocytes, monocytes, basophils, and eosinophils during inflammation and other immunoregulatory processes.

Recently, the C-C chemokine monocyte chemotactic protein1 (MCP-1) and the C-X-C chemokine IP-10 were shown to mediate antitumor effects in murine models (Rollins and Sunday, 1991; Walter et al., 1991; Luster and Leder, 1993). We designed experiments to test if the chemoattractant properties of RANTES for monocytes and $\mathrm{T}$ lymphocytes observed in vitro were relevant in an in vivo situation. In addition, we wished to investigate if the chemoattractant effects of RANTES in vivo would have an impact on the growth of solid tumors in a murine model system. Therefore, murine tumor cells were engineered to produce the human RANTES chemokine stably, and the ability of the modified tumor cells to form solid tumors in recipient animals was measured and compared to the growth of tumors from unmodified cells. We report here that RANTES-secreting immunogenic tumor cells fail to grow progressively in recipient animals and that this inhibition of growth is mediated through the actions of macrophages and $\mathrm{T}$ lymphocytes. Thus, the general chemoattractant properties exhibited by RANTES in vitro appear to be relevant in an in vivo model. Moreover, these properties suggest that the RANTES chemokine could play a role in the development of tumor vaccine or other antitumor strategies.

\section{MATERIALS AND METHODS}

\section{Animals}

Female C57BL/6 mice (B6), 10 to 12 weeks old, were obtained from the Animal Production Colonies, NCI Frederick
Cancer Research and Development Facility, National Institutes of Health (NIH), Frederick, MD.

\section{Tumors}

The weakly immunogenic MCA-205 sarcoma, syngeneic to B6 mice, was generated by i.m. injection of $0.1 \mathrm{ml}$ of $0.1 \%$ methylcholanthrene (MCA) in sesame seed oil as described previously (Parker and Rosenberg, 1977) and was maintained in vivo by serial passage. The WP-4 cell line that was used in these experiments is one of a series of clones derived from the MCA205 tumor.

Briefly, a single cell suspension of fresh MCA-205 tumor from the second transplant generation was prepared as described elsewhere (Mulé et al., 1985). Tumor clones were then grown in 96-well flat-bottomed tissue culture plates (Costar, Cambridge, MA) by limiting dilution technique at 0.3 cells/well. One such clone, designated WP-4. was maintained as a monolayer culture in complete medium (CM) containing RPMI-1640 (Biofluids, Rockville, MD), $0.1 \mathrm{mM}$ nonessential amino acids, $1.0 \mathrm{~m} M$ sodium pyruvate (both from Biofluids), $5 \times 10^{-5}$ M 2-mercaptoethanol (2-ME, Aldrich Chemical Co., Milwaukee, WI), $0.3 \%$ fresh L-glutamine, $100 \mathrm{U} / \mathrm{ml}$ penicillin, $100 \mu \mathrm{g} / \mathrm{ml}$ streptomycin (all from NIH media unit), $0.5 \mu \mathrm{g} / \mathrm{ml}$ amphotericin B (Flow Laboratories, McLean, VA), and 10\% heat-inactivated FCS (Biofluids).

\section{Human RANTES gene transfer into WP4 tumor cells}

A human RANTES cDNA fragment composed of base pairs 1-411 (Schall et al., 1990), containing the entire coding region including native signal peptide sequence of the RANTES protein, was subcloned into the mammalian expression vector pBJneo, which contains the selectable neomycin resistance gene.

The immunogenic WP4 tumor clone was transfected with the pBJneo-RANTES construct. Transfections were performed using the Stratagene $\mathrm{CaPO}_{4}$ transfection kit (La Jolla, CA). Briefly, $5 \times 10^{5}$ tumor cells were seeded on a 100 -mm petri dish (Falcon, Lincoln Park, NJ). Cells were cultured overnight in DMEM supplemented with $10 \%$ heat-inactivated fetal calf serum (FCS; both from Biofluids, Rockville, MD), $100 \mathrm{mM}$ glutamine, $100 \mathrm{U} / \mathrm{ml}$ penicillin, and $100 \mu \mathrm{g} / \mathrm{ml}$ streptomycin (all from NIH media unit). One to twenty micrograms of pBJneo-RANTES was added to the tumor cells in the presence of $\mathrm{CaPO}_{4}$ and incubated at $37^{\circ} \mathrm{C}, 3 \% \mathrm{CO}_{2}$ for $18-24 \mathrm{hr}$. After the incubation, medium was removed from petri dishes and washed twice with DMEM. Fresh medium was added and plates were cultured for $24 \mathrm{hr}$ at $37^{\circ} \mathrm{C}, 5 \% \mathrm{CO}_{2}$. Cells were split and allowed to incubate an additional $24 \mathrm{hr}$. Transfectants were selected by the addition of $400 \mu \mathrm{g} / \mathrm{ml}$ of the neomycin analog G418 (GIBCO, Grand Island, NY) and maintained thereafter in G418. Individual tumor clones were identified under the inverted microscope and removed from petri dishes using cloning cylinders (Bellco, Vineland, NJ). RANTES production by the clones was tested first by Western blot analysis of culture supernatants. RANTES protein production was then confirmed and quantitated by a RANTES-specific ELISA (Sadick $e t$ al., manuscript in preparation). Supernatants were collected from $5 \times 10^{5}$ cells $/ \mathrm{ml}$ cultured for $24 \mathrm{hr}$. 


\section{Generation of $\mathrm{CD} 8^{+}$tumor-infiltrating lymphocytes}

Subcutaneous MC-38 tumor (syngeneic to B6 mice) was harvested in a sterile fashion and crushed with the hub of a syringe. The tumor was then digested for $2 \mathrm{hr}$ at room temperature in Hank's balanced salt solution (HBSS) (Biofluids, Rockville, $\mathrm{MD}$ ) containing $0.01 \%$ hyaluronidase type $\mathrm{V}, 0.002 \%$ deoxyribonuclease type 1 , and $0.1 \%$ collagenase type IV (Sigma, St. Louis, MO) as described previously (Mulé et al., 1985). The mixture was passed through sterile 100-gauge nylon mesh (Nitex; Tetko, Inc., Elmsford, NY) to remove undigested fragments, and the resulting single cell suspension was then washed three times with HBSS after osmotic lysis of red blood cells with ACK lysing buffer (B \& B Research Laboratories Inc., Fiskeville, RI). To enrich for $\mathrm{T}$ cells, the suspension was then incubated for $45 \mathrm{~min}$ at $4^{\circ} \mathrm{C}$ with magnetic polystyrene beads (Dynal, Fort Lee, NJ) coated with anti-Thy 1.2 antibody as described previously (Yang et al., 1990). The bead-tumor-infiltrating lymphocytes (TIL) conjugates were magnetically isolated and placed into culture with recombinant interleukin-2 (IL-2) at 30-150 IU/ml in complete medium (CM). Recombinant interleukin-2 was kindly provided by the Chiron Corporation (Emeryville, CA) (sp. act. $=18 \times 10^{6} \mathrm{IU} / \mathrm{mg}$ protein). Twentyfour hours later (after spontaneous dissociation of TIL and magnetic beads), the TIL cultures were resuspended by shaking and the polystyrene beads were removed magnetically. The remaining TIL were placed back into culture with IL-2 at a concentration of $2.5 \times 10^{5}$ cells $/ \mathrm{ml}$ in 24-well culture plates. Autologous tumor cells (stored at $4^{\circ} \mathrm{C}$ for up to $24 \mathrm{hr}$ ) irradiated with $100 \mathrm{~Gy}$ (for growth inhibition) were added back to the TIL culture at a concentration of $2.5 \times 10^{5}$ cell $/ \mathrm{ml}$ as a source of antigenic stimulation. TIL cultures were subsequently restimulated every 10-14 days with freshly harvested and irradiated (30 Gy) tumor cell suspensions (which were lysed by TIL within $24 \mathrm{hr}$ ). By FACS analysis, the TIL utilized in the experiments were $>98 \%$ Thy $-1^{+}, \mathrm{CD}^{+}, \mathrm{CD}^{-}$and were cytotoxic in vitro, as reported previously (Yang et al., 1990).

\section{Tumor cell supernatants}

Supernatants were collected from cultured WP4 tumor lines after $24 \mathrm{hr}$ of incubation at $37^{\circ} \mathrm{C}$ at a cell density of 1 or $2 \times$ $10^{6} \mathrm{cells} / \mathrm{ml}$. Tissue culture was performed in CM using plastic tissue culture flasks (Flacon Plastics, Oxnard, CA) or 24well culture plates (Costar Corp., Cambridge, MA). Supernatants were collected after centrifugation at $1,500 \mathrm{rpm} \times$ $10 \mathrm{~min}$.

\section{In vitro chemotaxis assays}

A 48-well microchemotaxis chamber and thick nitrocellulose filter membrane with $5 \mu \mathrm{m}$-diameter pores (Neuro Probe, Cabin John, MD) was used to study motility of TIL (Averbook et al., 1993). Dilutions of tumor supernatants were placed into chambers above and below the filter membrane to generate concentration gradients or equilibrium conditions. Wells above the membrane contained cells being tested for chemotaxis at a concentration of $2 \times 10^{6}$ cells $/ \mathrm{ml}$ in $45 \mu \mathrm{l}$. $\mathrm{LL}-2$ was present in equal concentrations in the upper and lower wells of the apparatus to avoid effects from an $\mathrm{IL}-2$ gradient. The apparatus was incubated for $2 \mathrm{hr}$ at $37^{\circ} \mathrm{C}$ in $5 \% \mathrm{CO}_{2}$ in humidified chambers.
The membranes were removed, rinsed in a $10 \mathrm{~m} M$ buffered phosphate, $154 \mathrm{mM} \mathrm{NaCl}$ solution $\mathrm{pH} 7.2$, fixed with $18.5 \%$ formalin, stained with Mayer's hematoxylin (SIGMA Diagnostics, St. Louis, MO), and cleared with propanol and xylene. Membranes were placed on glass slides with type B immersion oil (Cargille, Cedar Grove, NJ) and cover slips then applied. Analysis was performed with a Zeiss Axioskop microscope (model D-7082 Zeiss; Oberkochen, Germany) using a video camera (Ikegami Electronics, Maywood, NJ) and an Optomax image analyzer (Model V from Optomax, Hollis, $\mathrm{NH}$ ). Beginning at the top of the filter, the number of cells per $200 \times$ high-powered field was measured at successive $10-\mu \mathrm{m}$ intervals down through the nitrocellulose filter. Each well ("spot") on the filter was measured in three random areas and each sample was tested in triplicate wells. Video gain and Optomax counting parameters were determined once for each filter and remained unchanged for reading all wells on that filter.

The following terms are defined:

1. Equilibrium conditions. Equal concentrations of a candidate factor above and below the filter membrane.

2. Positive gradient. Concentration of candidate factor in lower well greater than concentration in upper well.

3. Spontaneous migration. Cell migration with no factor above or below the filter membrane (CM and IL-2 only).

4. Chemokinetic effect. When migration under equilibrium conditions is greater than spontaneous migration but not significantly different from migration in a positive gradient.

5. Chemotactic effect. When migration in a positive gradient is significantly greater than both spontaneous migration and migration under equilibrium conditions.

Statistical analysis was performed using the Kruskal-Wallis nonparametric analysis of variance on averaged triplicate values. A significant difference in overall migration between two conditions required that significant differences in cell counts be seen at three of four consecutive depths.

\section{In vivo tumor model}

RANTES-secreting and control tumors were harvested from flasks with trypsin/versene (Biofluids). Syngeneic B6 mice (between 5 and 10 per group) were injected s.c. with $1 \times 10^{7}$ viable cells of each tumor (in a volume of $0.1 \mathrm{ml} \mathrm{HBSS}$ ). Tumor size, the product of the largest biperpendicular diameters, was measured with calipers at least twice weekly. All measurements were performed in a coded, blinded fashion, and were evaluated for significance between groups by Student's $t$-test. No animals were excluded from the calculated mean and SEM of tumor sizes shown in the figures and tables.

\section{In vivo depletion of $T$ cell subsets by monoclonal antibodies}

Hybridomas producing rat $\mathrm{IgG}_{2 \mathrm{~b}}$ monoclonal antibody (mAb) against the CD4 (GK1.5) and CD8 (2.43) cell-surface antigens were obtained from American Type Tissue Collection (Rockville, MD). The $2.43 \mathrm{mAb}$ was harvested as ascites from sublethally irradiated (500 rad) DBA/2 mice. The GK1.5 mAb was purified from concentrated culture supernatants using am- 
monium sulfate precipitation. For in vivo cell depletions, B6 mice each received one i.v. injection of $1.0 \mathrm{ml}$ diluted $\mathrm{mAb}$, in which $0.2 \mathrm{ml}$ of 2.43 monoclonal ascites fluid, or $300 \mu \mathrm{g}$ of GK1.5 mAb was mixed with HBSS, $24 \mathrm{hr}$ before tumor injection. Lymphocyte subset depletion (complete) was verified by flow cytometric analysis for CD4- and CD8-expressing cells of fresh splenocytes of mice receiving injections 2-4 days previously with $\mathrm{mAb}$. Injection of diluted ascites containing an $\mathrm{IgG}_{2 \mathrm{a}}$ mAb (1A14, a gift from Dr. Richard B. Alexander, National Cancer Institute), directed against the Thy-1.1 T cell antigen, served as an irrelevant control, as described previously (Karp et al., 1993). Experimental groups contained between 5 and 10 mice.

\section{In vivo blockade of adhesion-promoting receptor on macrophages by $5 C 6 \mathrm{mAb}$}

Purified 5C6 (Hutchings et al., 1990) mAb was kindly provided by Drs. M. Stein and S. Gordon (Sir William Dunn School of Pathology, Oxford University, Oxford, UK). 5C6 mAb was diluted in HBSS to $400-500 \mu \mathrm{g} / \mathrm{ml}$ and each mice received 1 $\mathrm{ml}$ of diluted $5 \mathrm{C} 6 \mathrm{mAb}$ i.v. beginning $24 \mathrm{hr}$ before the s.c. injection of tumor cells. Subsequent injections of $5 \mathrm{C} 6 \mathrm{mAb}$ were given i.p. every other day for five total injections.

\section{RESULTS}

Stable RANTES chemokine production by genetically modified WP4 tumor cells was obtained following cDNA transfer by transfection. Tumor cell lines established from picked colonies growing in G418 selection media were screened for RANTES chemokine secretion by Westem blot analysis and ELISA. Four lines (WP4-1, WP4-2, WP4-3, and WP4-12) were chosen for further study. The transfectants WP4-2 and WP4-3 failed to secrete detectable quantities of RANTES, whereas WP4-1 and WP4-12 secreted $\geq 50 \mathrm{ng} / \mathrm{ml}$ and $\geq 130 \mathrm{ng} / \mathrm{ml}$ (per $5 \times 10^{5}$ cells per $24 \mathrm{hr}$ ), respectively. These levels of RANTES production were stable in vitro for at least 5 months (the extent of the duration of testing). Unmodified parental WP4 tumor cells (WP4-no vector; WP4-NV) as well as those transfected with the PBJ-neo construct only (WP4-NEO) were negative for RANTES production (not shown).

The RANTES chemokine detected in WP4-1 and WP4-12 supernatants by Western blot and ELISA was then evaluated for biologic function. Comparisons were made between supernatants derived from cultures of the nonsecreting control (WP4NV, WP4-NEO) tumor cells and the RANTES-secreting WP41 and WP4-12 tumor cells, as well as purified recombinant human RANTES. Murine TIL migration in response to these test substances in vitro was chosen as the parameter, as described previously (Averbook et al., 1993). TIL chemotaxis was tested utilizing a 48-well microchemotaxis chamber assay where tumor cell supernatants were tested at concentrations of 50,25 , and $15 \%$ of the neat supernatant, and purified bacterially derived recombinant human RANTES was used at a final concentration of $5 \mathrm{ng} / \mathrm{ml}$. All experiments were done in a blinded fashion. The results from a representative experiment are shown in Fig. 1. Purified recombinant human RANTES pro- tein elicited a strong chemotactic response in all cases (Fig. 1A-D), whereas equilibrium conditions showed no significant migration (not shown). Supernatants from the WP4-NV tumor did not show any significant chemotactic activity (Fig. 1A). Although the WP4-NEO tumor supernatant showed a small degree of chemotactic activity at high concentrations (Fig. 1B), this effect was always much less than that seen in response to purified RANTES or the RANTES-containing supernatants. This WP4-NEO chemoattractant activity could be attributed possibly to the secretion of an endogenous chemotactic factor, as described previously (Averbook et al., 1993). The difference in chemotactic activity between the WP4-NEO cells (i.e., minimal effect) versus nontransfected parental WP4 cells (i.e., no effect) might reflect the outgrowth of a selected Neo-resistant clone with endogenous chemotactic factor secretion that is also resident in the more heterogeneous parental tumor line but at a frequency below detection by the microchemotaxis assay. Culture supernatants from both RANTES-secreting tumor lines (WP4-1 and WP4-12) demonstrated marked chemotaxis for the MC-38 TIL (Fig. 1C and Fig. 1D, respectively). Thus, human RANTES secreted from transfected WP4 tumor cells had potent chemotactic activity in vitro for murine Thy $-1^{+} / \mathrm{CD} 8^{+} \mathrm{TL}$. Although not apparent in this particular example, in other experiments the chemotactic activity of culture supernatants of RANTES gene-modified tumor cells was titratable (data not shown).

The in vitro growth profiles of the WP4-1 and WP4-12 RANTES-secreting tumor cell clones were compared to the nonsecreting cell clones WP4-2 and WP4-3 and to WP4-NEO. The growth rates of the clones in culture were unaffected by their ability to secrete human RANTES (not shown). After 10 days, the number of cells in each culture was not significantly different. Thus, the presence of RANTES did not appear to have any direct affect on the ability of WP4 cells to proliferate in culture. In addition, RANTES-secreting tumor cells did not have altered levels of MHC class I as determined by FACS (not shown).

We next tested the ability of the RANTES-secreting WP4 tumor cells to form solid tumor masses in recipient animals after injection. Ten million cells from each of the two RANTESsecreting cultures (WP4-1, WP4-12), the nonsecreting tumors (WP4-2, WP4-3), or the transfection control (WP4-NEO) were injected subcutaneously in the back of recipient mice and the incidence of tumor formation in each group was followed over time. In every case, mice injected with the RANTES-secreting tumor cells failed to develop detectable solid tumor masses out to day 51 whereas all other mice developed large tumor masses (Table 1). Moreover, tumor-free mice $(n=12)$ in the WP-1 and WP-12 RANTES-secreting tumor groups all rejected a subsequent lethal challenge dose $\left(1 \times 10^{5}\right)$ of unmodified WP4 parental tumor cells given s.c. and remained tumor-free for at least 100 days of observation. Thus, tumor immunity was elicited in vivo by the administration of RANTES-secreting WP4 tumor cells.

To determine if immune effector cells were involved in the inhibition of solid tumor formation, we undertook to deplete or inhibit the function of various immune cells by the administration of monoclonal antibodies to animals receiving RANTESsecreting tumor cells. To deplete $\mathrm{CD}^{+}$and $\mathrm{CD8}{ }^{+} \mathrm{T}$ cell pop- 

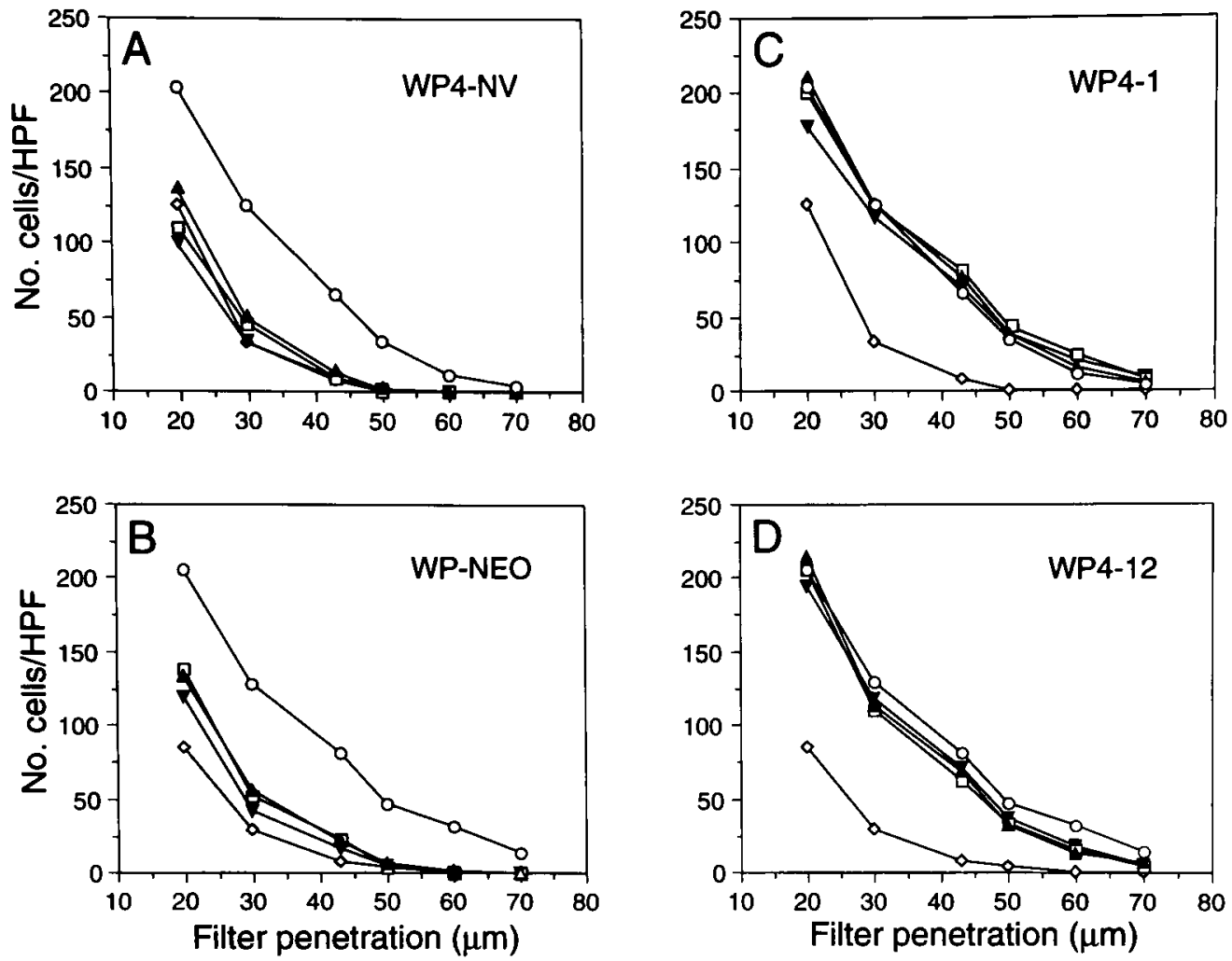

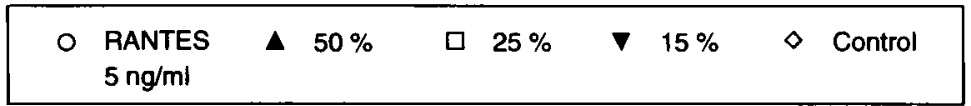

FIG. 1. Chemoattractant activity of recombinant human RANTES and cell culture supernatants from WP4 transfectants for murine TIL. Results of in vitro chemotaxis assays employing thick filters where two parameters are measured: number of cells responding counted per high-power field (No./HPF; $y$ axis) versus depth of penetration of the cells into the filter ( $x$ axis). The number of $\mathrm{CD} 8^{+} /$Thy $-1.2^{+}$murine TIL reponding to diluted cell culture supernatants from parental WP4 cells containing no vector (A), WP4 cells stably transfected with a NEO containing vector alone (B), and two transfectants that are stably producing RANTES, WP4-1 (C) and WP4-12 (D) are plotted and compared in each case to the number of cells responding to purified RANTES or control medium. Dilutions are represented as percent of neat supernatant. Migration of TIL in response to purified recombinant RANTES and to supernatants from WP4-1 and WP4-12 cells was significant $(p<0.05)$ as assessed by Kruskal-Wallis nonparametric analysis of variance on averaged triplicate values.

Table 1. Rantes-Secreting MCA-205 (WP4) Tumors FaIl to Grow Progressively

\begin{tabular}{lccc}
\hline & & \multicolumn{2}{c}{ Tumor incidence } \\
\cline { 3 - 4 } tramsfectants $^{\mathrm{a}}$ & $\begin{array}{c}\text { RANTES- } \\
\text { secreting }\end{array}$ & Day 21 & Day 51 \\
\hline WP4-1 & + & $0 / 6^{\mathrm{b}}(0 \pm 0)^{\mathrm{c}}$ & $0 / 6(0 \pm 0)$ \\
WP4-2 & - & $6 / 6(9 \pm 1)$ & $6 / 6(16 \pm 2)$ \\
WP4-3 & - & $6 / 6(7 \pm 1)$ & $6 / 6(11 \pm 1)$ \\
WP4-12 & + & $0 / 6(0 \pm 0)$ & $0 / 6(0 \pm 0)$ \\
WP4-NEO & - & $6 / 6(8 \pm 1)$ & $6 / 6(14 \pm 1)$
\end{tabular}

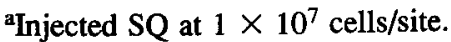

bNumber with tumor/total.

Mean tumor diameter $(\mathrm{mm} \pm \mathrm{SEM})$. ulations, the mAbs GK1.5 and 2.43, respectively, were administered. In addition, we employed the $5 \mathrm{C} 6 \mathrm{mAb}$, which has been shown to inhibit the migration of mouse macrophages in vivo effectively (Hutchings et al., 1990).

In the first set of experiments, the inhibition of macrophage migration by the administration of the 5C6 antibody fully restored the ability of RANTES-secreting cells to form solid tumors in recipient animals (Fig. 2A). In all animals that received both the WP4-12 cells and the 5C6 antibody, tumors developed very similary to those in the controls animals that had been injected with WP4-NEO cells. By contrast, no tumors formed in animals receiving WP4-12 cells in the absence of 5C6. Similarly, the tumorigenicity of RANTES-secreting WP4-12 cells could also be restored by the depletion of $T$ cell subsets (Fig. 2B). Administration of the anti-CD4 antibody rescued tumor growth in recipient animals, though these tumors were 
A

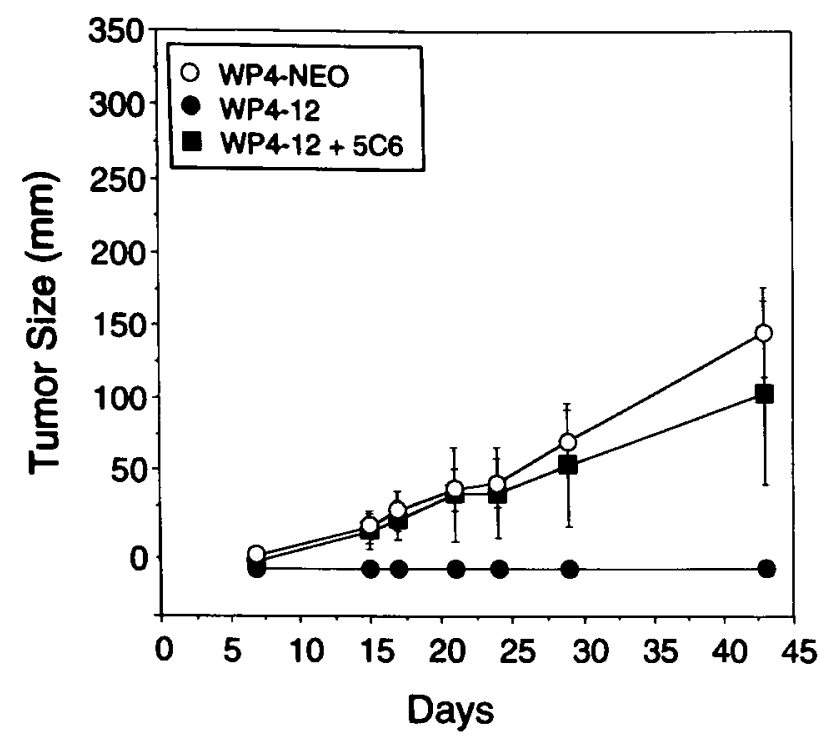

B

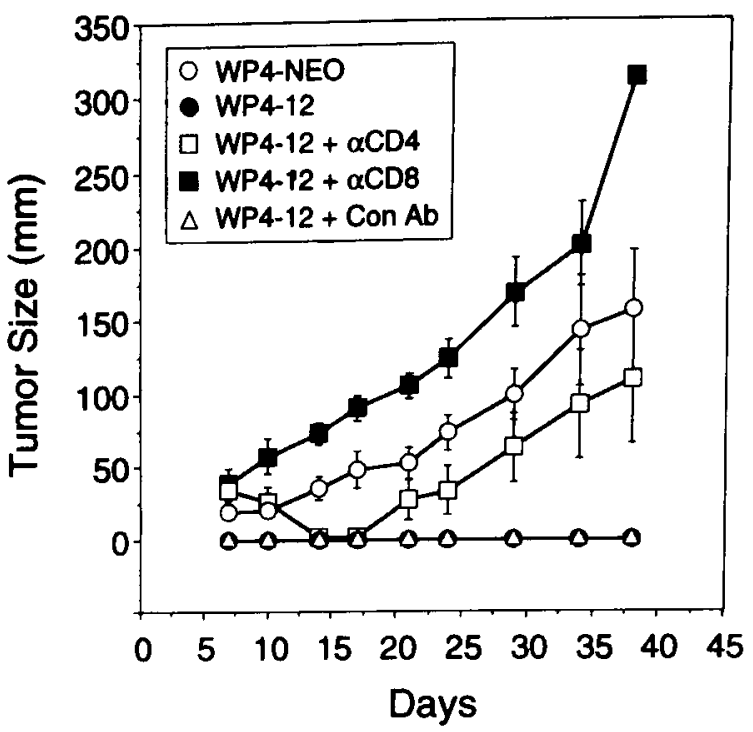

C

\begin{tabular}{|c|c|c|c|}
\hline $\begin{array}{l}\text { Tumor Injected } \\
\text { S.C. }\end{array}$ & $\begin{array}{l}\text { mAb } \\
\text { I.V.A.P }\end{array}$ & $\begin{array}{l}\text { No. Mice with Tumor/ } \\
\text { Total }\end{array}$ & $\begin{array}{l}\text { Tumor Diameter in } \mathrm{mm} \\
(\mathrm{X} \pm \mathrm{SEM})\end{array}$ \\
\hline WP4-Neo & - & $10 / 10$ & $8.3 \pm 1.4$ \\
\hline WP4-RANTES & - & $0 / 5$ & $0 \pm 0$ \\
\hline WP4-RANTES & irrel. & $0 / 5$ & $0 \pm 0$ \\
\hline WP4-RANTES & $2.43(\alpha \mathrm{CD} 8)$ & $5 / 5$ & $10.9 \pm 1.2$ \\
\hline WP4-RANTES & GK1.5 ( $\alpha$ CD4) & $4 / 6$ & $3.0 \pm 1.5$ \\
\hline WP4-RANTES & $5 \mathrm{C6}(\alpha \mathrm{CR} 3)$ & $5 / 5$ & $13.0 \pm 1.8$ \\
\hline
\end{tabular}

FIG. 2. Identification of host immune cell populations mediating growth inhibition of RANTES-secreting tumor cells. Measurements of tumor size in recipient animals is plotted over time. A. Comparison of tumor growth in animals receiving WP4NEO cells, WP4-12 (RANTES-secreting) cells, and a combination of WP4-12 cells and the 5C6 antibody. B. Comparison of tumor growth over time in animals receiving WP4-NEO and WP4-12 cells alone and WP4-12 cells in combination with antibodies depleting either $\mathrm{CD}^{+}$or $\mathrm{CD}^{+} \mathrm{T}$ cells, as well as a control (anti-Thy 1.1) antibody. C. A summary of the results of a second similar experiment where tumor incidence and size in recipient animals were evaluated after 4 weeks.

somewhat smaller than those in control animals. Anti-CD8 antibody treatment also completely restored tumorigenicity, resulting in tumors that were in this experiment larger than those in the controls (Fig. 2B). A separate set of animals yielded similar results, as summarized in Fig. 2C. Again, administration of either the anti-CD8 or $5 \mathrm{C} 6$ antibodies fully restored the ability of the RANTES-secreting cells to form solid tumors in recipient animals whereas the depletion of $\mathrm{CD}^{+} \mathrm{T}$ cells resulted in a partial restoration of tumorigenicity (Fig. 2C). In this second set of animals, anti-CD4 treatment resulted in tumors in four of six recipients and these tumors were significantly smaller than in the control (WP4-NEO) animals, whereas 5C6 treatment resulted in significantly larger tumors. In no case did tumors form in animals receiving an irrelevant (anti-Thy-1.1) mAb treatment (Fig. 2B and 2C). Thus, the ability of RANTES to inhibit tumor growth is mediated through the participation of immune cells.

\section{DISCUSSION}

The C-C chemokine RANTES has been shown to be a potent chemoattractant for human monocytes and $\mathrm{T}$ cells in vitro (Schall et al., 1990). We undertook to examine its properties in vivo using a murine tumor model. This report shows that immunogenic murine tumor cells that stably produce the human 
RANTES chemokine lose their ability to form solid tumor masses in vivo. Furthermore, this loss of tumorigenicity appears to be mediated by various immune cells because the tumorigenicity of RANTES-secreting cells in vivo is restored when $\mathrm{CD}^{+}$and $\mathrm{CD}^{+} \mathrm{T}$ cells are depleted or when murine macrophage migration is inhibited. Thus, this study represents the first analysis of the functions of RANTES as produced from an in vivo source, and shows that the chemoattractant properties of this chemokine for monocytes and $T$ cells as predicted from in vitro assays using human cells appear to be broadly relevant in this in vivo murine model.

Although the predictions of the chemoattractant potential of RANTES for leukocytes subsets obtained from both in vitro and in vivo experimental approaches generally correlate, some differences can been noted. For example, the original report describing human RANTES as a chemoattractant for human monocytes and $\mathrm{T}$ cells suggested a preferential attraction of predominantly $\mathrm{CD}_{4}{ }^{+}$cells of the memory phenotype $\left(\mathrm{CD} 45 \mathrm{RO}^{+}\right.$; Schall et al., 1990), whereas the data presented here suggest that human RANTES attracts murine $\mathrm{CD}^{+} \mathrm{TIL}$ in vitro and also affects murine $\mathrm{CD}^{+}$function in vivo. These differences could be attributed to several factors. First, there may exist differences in the fine specificity of the chemokine between human and murine species. Second, CD8 ${ }^{+}$TIL may be preferentially migrating in response to RANTES at the specific concentrations of chemokine used in these experiments. Concentration-dependent specificity of attraciton for T cell subsets has been described for the related chemokine human MIP$1 \alpha$ (Schall et al., 1993). Last, RANTES may be exhibiting only an ability to preferentially attract $T$ cells of the memory or "experienced" phenotype. This is consistent with the results of both studies, because the $\mathrm{CD} 8^{+}$murine TIL are clearly "experienced" with respect to their ability to recognize tumor cells and are therefore likely to be of the memory phenotype. Further experiments are underway to examine this question more fully.

The restoration of tumor growth by all treatments with antibodies that inhibit $\mathrm{T}$ lymphocyte and macrophage function suggests that RANTES can mediate the cooperation of these leukocyte populations in antitumor defense. The details of this network are not yet clear but the experiments presented here may provide some clues. It is interesting that depletion of either $\mathrm{CD}^{+}$or $\mathrm{CD}^{+} \mathrm{T}$ cells or the inhibition of the migration of macrophages all result in tumor growth, but subtle differences in the results obtained by the three different antibody treatments may be important. For example, treatment with the anti-CD4 antibody results in only a partial restoration of tumorigenicity by RANTES-secreting tumors. Anti-CD8 treatment, however, or the inhibition of macrophage migration by the $5 \mathrm{C} 6$ antibody, restores the tumorigenicity of RANTES-secreting cells in all animals, and the resulting tumor masses are as large or larger than those found in control mice receiving WP4-NEO cells, which do not secrete RANTES. Thus, it is possible that macrophages and $\mathrm{CD} 8^{+} \mathrm{T}$ cells have primary roles in antitumor defense in this model, and the involvement of $\mathrm{CD} 4^{+} \mathrm{T}$ cells is important but perhaps not essential. Because macrophages and distinct subsets of $T$ cells may each have varying levels of importance in mediating the rejection process, depending on whether the host immune system is "naive" or previously sensitized to tumor, additional studies are needed to evaluate the effects of RANTES in models of vaccination and of treatment of established tumors. It should also be noted that though 5C6 has been characterized as an antibody that inhibits macrophage migration (Hutchings et al., 1990), we cannot exclude a role for other $\mathrm{CR}^{+}{ }^{+}$cells that $5 \mathrm{C} 6$ is likely to recognize.

The importance of $\mathrm{CD}^{+} \mathrm{T}$ cells in the abrogation of tumor growth in the presence of RANTES is supported by other observations. We have performed a set of experiments where, rather than using immunogenic WP4 cells, we have engineered a nonimmunogenic tumor cell line, $4 \mathrm{JK}$ (a clone of the MCA102 sarcoma; Karp et al., 1993), to produce RANTES stably. Injection of such RANTES-producing, nonimmunogenic tumor cells (producing $>50-200 \mathrm{ng} / \mathrm{ml}$ per $5 \times 10^{5}$ cells over a 24 hr period) into recipient animals does indeed result in the consistent formation of solid tumors, but those tumors are more slowly growing $(0.9 \mathrm{~cm}$ in mean diameter at day 19 after tumor injection) than those in control animals $(1.8 \mathrm{~cm}$ in mean diameter also at day 19). Thus, the immunogenicity of the parent tumor cell may be important in the ability of the RANTES chemokine to eradicate tumor growth in vivo.

One possibility is that in this system the immunogenic tumor engenders a strong endogenous $T$ cell response, resulting in antitumor memory $\mathrm{T}$ cells, which are then recruited effectively to the nascent tumor by RANTES. Nonimmunogenic tumors would not trigger the same level of $T$ cell reaction, but their growth might still be inhibited by virtue of the capacity of RANTES to attract a clone(s) of reactive T cells at low frequency in the periphery as well as monocytes/macrophages.

In preliminary immunization/challenge experiments, we have not observed any discernible increase in the capacity of irradiated RANTES-secreting WP4 (or 4JK) tumor cells to immunize naive mice compared to its counterpart irradiated control parental line. Therefore, the secretion of large amounts of this chemokine per se does not appear to increase the inherent immunogenicity of this particular tumor; similar results have been obtained with the nonimmunogenic $4 \mathrm{JK}$ tumor line as well. Thus, the in vivo antitumor effect of RANTES is more likely to be a direct result of its chemotactic function on host immune cells. Further experimentation is necessary to elucidate the details of the mechanisms through which RANTES mediates its immune cell dependent antitumor effects. In this regard, RANTES has recently been shown to mediate direct activation of T cells (Bacon et al., 1995).

Another $\mathrm{C}-\mathrm{C}$ chemokine that has been reported to have an effect on the growth of tumors is MCP-1. Although it has been shown that MCP-1-modified Chinese hamster ovary (CHO) cells will not form tumors in immunodeficient nude mice (Rollins and Sunday, 1991) and that MCP-1 transduction of a murine sarcoma correlates with a slower growth rate and an increased macrophage content of the resulting neoplasms in BALB/c mice (Walter et al., 1991), neither of those studies has reported the ablation of tumor growth in immunocompetent mice. In addition, neither dissects the immune mechanism of tumor inhibition, although both reports document an increase macrophage involvement in MCP-1-transduced tumors. Although direct comparisons of the MCP-1 reports and the current study regarding RANTES are obviously flawed, it is interesting to speculate that RANTES may be exhibiting a more potent antitumor effect by virtue of its ability to affect $\mathrm{T}$ lym- 
phocyte as well as macrophage recruitment and/or function. By contrast, the action of MCP-1 has been largely thought to be restricted to macrophages. A recent report by Luster and Leder (1993) demonstrated that the C-X-C chemokine IP-10 can inhibit tumor growth in vivo. In that study, the effect of IP-10 was shown to be thymus dependent, but, unlike the present study, the mechanism of tumor inhibition was not delineated, and in vivo depletion of immune cell populations had not been performed. Direct comparisons between chemokines using the same cell lines and the same strains of immunocompetent mice would undoubtedly be of use in determining the relative antitumor efficacies of the various members of the superfamily.

In summary, we have shown that murine tumor cells that have been engineered to produce the RANTES chemokine stably have a loss of tumorigenic capacity in vivo. This lack of tumorigenicity seems correlated with the function of $T$ cells and macrophages in the host animal and level of inherent immunogenicity of the tumor. Thus, the chemoattractant activities ascribed to the RANTES molecule from in vitro studies may be relevant to in vivo immune trafficking processes, and these properties might be exploited in certain antitumor strategies that employ vaccines.

\section{ACKNOWLEDGMENTS}

Many thanks to David Jones for his excellent technical assistance, Drs. Michael Stein and Satish Keshav for helpful suggestions regarding the 5C6 antibody, and John Mak and Michael Sadick for early help in evaluating the WP4 supernatants. We also wish to thank Evelyn Berry and Sarah Wiener for assistance in preparing the manuscript and Louis Tamayo for making the figures.

\section{REFERENCES}

AVERBOOK, B.J., WEI, J.P., PERRY-LALLEY, D.M., ROSENBERG, S.A., and YANG, J.C. (1993). A tumor-elaborated supernatant factor chemotactic for IL-2 expanded tumor infiltrating T-lymphocytes. Lymphokine Cytokine Res. 12, 1-8.

BACON, K.B., PREMACK, B.A., GARGNER, P., and SCHALL, T.J. (1995). Activation of dual $T$ cell signaling pathways by the chemokine RANTES. Science 269, 1727-1730.

BISCHOFF, S.C., KRIEGER, M., BRUNNER, T., and DAHINDEN, C.A. (1992). Monocyte chemotactic protein 1 is a potent activator of human basophils. J. Exp. Med. 175, 1271-1275.

GAO, J.-L., KUHNS, D.B., TIFFANY, H.L., McDERMOTT, D., LI, X., FRANCKE, U., and MURPHY, P.M. (1993). Structure and functional expression of the human macrophage inflammatory protein $1 \alpha /$ RANTES receptor. J. Exp. Med. 177, 1421-1427.

HOLMES, W.E., LEE, J., KUANG, W.-J., RICE, G.C., and WOOD, W.I. (1991). Structure and functional expression of a human interleukin-8 receptor. Science 253, 1278-1280.

HUTCHINGS, P., ROSEN, H., O'REILY, L., SIMPSON, E., GORDON, S., and COOKE, A. (1990). Transfer of diabetes in mice prevented by blockade of adhesion-promoting receptor on macrophages. Nature 348, 639-642.
KAMEYOSHI, Y., DÖRSCHNER, A., MALLET, A.I., CHRISTOPHERS, E., and SCHRÖDER, J.-M. (1992). Cytokine RANTES released by thrombin-stimulated platelets is a potent attractant for human eosinophils. J. Exp. Med. 176, 587-592.

KARP, S.E., FARBER, A., SALO, J.C., HWU, P., JAFFE, G., ASHER, A.L., SHILONI, E., RESTIFO, N.P., MULÉ, J.J., and ROSENBERG, S.A. (1993). Cytokine secretion by genetically modified nonimmunogenic murine fibrosarcoma: tumor inhibition by $\mathbb{I L}-2$ but not TNF. J. Immunol. 150, 896-908.

KELNER, G.S., KENNEDY, J., BACON, K.B., KLEYENSTEUBER, S., LARGAESPADA, D.A., JENKINS, N.A., COPELAND, N.G., BAZAN, J.F., MOORE, K.W., SCHALL, T.J., and ZLOTNICK, A. (1994). Lymphotactin: A cytokine that represents a new class of chemokine. Science 266, 1395-1398.

KENNEDY, J., KELNER, G.S., KLEYENSTEUBER, S., SCHALL, T.J., WEISS, M.C., YSSEL, H., SCHNEIDER, P.V., COCKS, B.G., BACON, K., and ZLOTNICK, A. (1995). Molecular cloning and functional characterization of human lymphotactin. J. Immunol. 155, 203-209.

KUNA, P., REDDIGARI, S.R., RUCINSKI, D., OPPENHEIM, J.J., and KAPLAN, A.P. (1992a). Monocyte chemotactic and activating factor is a potent histamine-releasing factor for human basophils. J. Exp. Med. 175, 489-493.

KUNA, P., REDDIGARI, S.R., SCHALL, T.J., RUCINSKI, D., VIKSMAN, M.Y., and KAPLAN, A.P. (1992b). RANTES, a monocyte and $\mathrm{T}$ lymphocyte chemotactic cytokine releases histamine from human basophils. J. Immunol. 149, 636-642.

LUSTER, A.D., and LEDER, P. (1993). IP-10. a C-X-C chemokine elicits a potent thymus-dependent antitumor response in vivo. J. Exp. Med. 178, 1057-1065.

MÜÉ, J.J., SHU, S., and ROSENBERG, S.A. (1985). The anti-tumor efficacy of lymphokine-activated killer cells and recombinant interleukin-2 in vivo. J. Immunol. 135, 646-652.

MURPHY, P.M., and TIFFANY, H.L. (1991). Cloning of complementary DNA encoding a functional human interleukin-8 receptor. Science 253, 1280-1283.

NEOTE, K., DIGREGORIO, D., MAK, J.Y., HORUK, R., and SCHALL, T.J. (1993). Molecular cloning, functional expression, and signaling characteristics of a C-C chemokine receptor. Cell 72, 415-425.

OPPENHEIM, J.J., ZACHARIAE, C.O., MUKAIDA, N., and MATSUSHIMA, K. (1991). Properties of the novel proinflammatory supergene "intercrine" cytokine family. Annu. Rev. Immunol. 9, 617-648.

PARKER, G.A., and ROSENBERG, S.A. (1977). Serologic identification of multiple tumor-associated antigens on murine sarcomas. J. Natl. Cancer Inst. 58, 1303-1309.

ROLLINS, B.J., and SUNDAY, M.E. (1991). Suppression of tumor formation in vivo by expression of the $J E$ gene in malignant cells. Mol. Cell. Biol. 11, 3125-3131.

ROT, A., KREIGER, M., BRUNNER, T., BISCHOFF, S.C., SCHALL, T.J., and DAHINDEN, C.A. (1992). RANTES and macrophage inflammatory protein $1 \alpha$ induce the migration and activation of normal human eosinophil granulocytes. J. Exp. Med. 176, 1489-1495.

SCHALL, T.J. (1991). Biology of the RANTES/SIS cytokine family. Cytokine 3, 165-183.

SCHALL, T.J. (1994). The chemokines. In The Cytokine Handbook, 2nd ed. A. Thomson, ed. (Academic Press, New York), pp. 419-460. SCHALL, T.J., BACON, K., TOY, K.J., and GOEDDEL, D.V. (1990). Selective attraction of monocytes and T lymphocytes of the memory phenotype by cytokine RANTES. Nature 347, 669-671.

SCHALL, T.J., BACON, K., CAMP, R.D.R., KASPARI, J.W., and GOEDDEL, D.V. (1993). Human macrophage inflammatory protein $\alpha$ (MIP- $1 \alpha)$ and MIP- $1 \beta$ chemokines attract distinct populations of lymphocytes. J. Exp. Med. 177, 1821-1826. 
TANAKA, Y., ADAMS, D.H., HUBSCHER, S., HIRANO, H., SIEBENLIST, U., and SHAW, S. (1993). T-cell adhesion induced by proteoglycan-immobilized cytokine MIP-1 $\beta$. Nature 361, 79-82.

TAUB, D., CONLON, D., LLOYD, A., OPPENHEMM, J., and KELVIN, D. (1993). Preferential migration of activated $\mathrm{CD}^{+}{ }^{+}$and $\mathrm{CD}^{+} \mathrm{T}$ cells in response to MIP-1 $\alpha$ and MIP-1 $\beta$. Science 260, 355-358.

WALTER, S., BOTTAZZI, B., GOVONI, D., COLOTTA, F., and MANTOVANI, A. (1991). Macrophage infiltration and growth of sarcoma clones expressing different amounts of monocyte chemotactic protein/JE. Int. J. Cancer 49, 431-435.

YANG, J.C., PERRY-LALLEY, D., and ROSENBERG, S.A. (1990). An improved method for growing murine tumor infiltrating lym- phocytes with in vivo anti-tumor activity. J. Biol. Response Modifiers 9, 149-159.

Address reprint requests to: Dr. James J. Mulé

Department of Surgery MSRB-I, Rm. 1520C

University of Michigan 1150 W. Medical Center Dr. Ann Arbor, MI 48103-0666

Received for publication February 20, 1996; accepted after revision May 28, 1996. 
This article has been cited by:

1. Natalia Lapteva, Melissa Aldrich, David Weksberg, Lisa Rollins, Tatiana Goltsova, Si-Yi Chen, Xue F. Huang. 2009. Targeting the Intratumoral Dendritic Cells by the Oncolytic Adenoviral Vaccine Expressing RANTES Elicits Potent Antitumor Immunity. Journal of Immunotherapy 32:2, 145-156. [CrossRef]

2. Jian-Qing Gao, Yasuhiro Tsuda, Min Han, Dong-Hang Xu, Naoko Kanagawa, Yutaka Hatanaka, Yoichi Tani, Hiroyuki Mizuguchi, Yasuo Tsutsumi, Tadanori Mayumi, Naoki Okada, Shinsaku Nakagawa. 2009. NK cells are migrated and indispensable in the anti-tumor activity induced by CCL27 gene therapy. Cancer Immunology, Immunotherapy 58:2, 291-299. [CrossRef]

3. Jian-Qing Gao, Naoko Kanagawa, Dong-Hang Xu, Min Han, Toshiki Sugita, Yutaka Hatanaka, Yoichi Tani, Hiroyuki Mizuguchi, Yasuo Tsutsumi, Tadanori Mayumi, Naoki Okada, Shinsaku Nakagawa. 2008. Combination of two fiber-mutant adenovirus vectors, one encoding the chemokine FKN and another encoding cy tokine interleukin 12, elicits notably enhanced anti-tumor responses. Cancer Immunology, Immunotherapy 57:11, 1657-1664. [CrossRef]

4. Josée Golay, Martino Introna. 2008. Chemokines and antagonists in non-Hodgkin's lymphoma. Expert Opinion on Therapeutic Targets 12:5, 621-635. [CrossRef]

5. Karin Jöhrer, Lisa Pleyer, Angelika Olivier, Eva Maizner, Claudia Zelle-Rieser, Richard Greil. 2008. Tumour-immune cell interactions modulated by chemokines. Expert Opinion on Biological Therapy 8:3, 269-290. [CrossRef]

6. Masakazu OKAMOTO, Kazuyoshi IMAIZUMI, Yoshinori HASEGAWA, Naozumi HASHIMOTO, Atsushi SUMIDA, Masataka SHIBAZAKI, Kenzo TAKAGI, Kaoru SHIMOKATA, Tsutomu KAWABE. 2007. Macrophage-derived chemokine in malignant and tuberculous pleural effusions. Respirology 12:4, 581-584. [CrossRef]

7. Thomas F. Gajewski, Yuru Meng, Christian Blank, Ian Brown, Aalok Kacha, Justin Kline, Helena Harlin. 2006. Immune resistance orchestrated by the tumor microenvironment. Immunological Reviews 213:1, 131-145. [CrossRef]

8. Seitaro Hirano, Yukio Iwashita, Atsushi Sasaki, Seiichiro Kai, Masayuki Ohta, Seigo Kitano. 2006. Increased mRNA expression of chemokines in hepatocellular carcinoma with tumor-infiltrating lymphocytes. Journal of Gastroenterology and Hepatology, ahead of print060726060227001-???. [CrossRef]

9. Gayle G. Vaday, Donna M. Peehl, Pournima A. Kadam, Diana M. Lawrence. 2006. Expression of CCL5 (RANTES) and CCR5 in prostate cancer. The Prostate 66:2, 124-134. [CrossRef]

10. Jiali Li, Peisheng Hu, Leslie Khawli, Alan Epstein. 2003. Journal of Immunotherapy 26:4, 320-331. [CrossRef]

11. Bela Bodey. 2002. Spontaneous regression of neoplasms: new possibilities for immunotherapy. Expert Opinion on Biological Therapy 2:5, 459-476. [CrossRef]

12. Bernhard Homey, Anja Müller, Albert Zlotnik. 2002. CHEMOKINES: AGENTS FOR THE IMMUNOTHERAPY OF CANCER?. Nature Reviews Immunology 2:3, 175-184. [CrossRef]

13. K. Wetzel, P. Menten, G. OpdDnakker, J. Van Damme, H. J. GrDne, N. Giese, A. Vecchi, S. Sozzani, J. J. Cornelis, J. Rommelaere, C. Dinsart. 2001. Transduction of human MCP-3 by a parvoviral vector induces leukocyte infiltration and reduces growth of human cervical carcinoma cell xenografts. The Journal of Gene Medicine 3:4, 326-337. [CrossRef]

14. Tetsuhiko Nomura, Hitoshi Hasegawa, Masashi Kohno, Miho Sasaki, Shigeru Fujita. 2001. Enhancement of anti-tumor immunity by tumor cells transfected with the secondary lymphoid tissue chemokine EBI-1-ligand chemokine and stromal cell-derived factor-1achemokine genes. International Journal of Cancer 91:5, 597-606. [CrossRef]

15. P.C.R. Emtage , Y. Wan , M. Hitt , F.L. Graham , W.J. Muller , A. Zlotnik , J. Gauldie . 1999. Adenoviral Vectors Expressing Lymphotactin and Interleukin 2 or Lymphotactin and Interleukin 12 Synergize to Facilitate Tumor Regression in Murine Breast Cancer ModelsAdenoviral Vectors Expressing Lymphotactin and Interleukin 2 or Lymphotactin and Interleukin 12 Synergize to Facilitate Tumor Regression in Murine Breast Cancer Models. Human Gene Therapy 10:5, 697-709. [Abstract] [PDF] [PDF Plus] 